\title{
Morphological and Functional Imaging for Detecting and Assessing the Resectability of Neuroendocrine Liver Metastases
}

\author{
Maxime Ronot ${ }^{\mathrm{a}-\mathrm{c}}$ Ashley K. Clift ${ }^{\mathrm{d}}$ Richard P. Baum ${ }^{\mathrm{e}}$ Aviral Singh $^{\mathrm{e}}$ \\ Harshad R. Kulkarni ${ }^{e}$ Andrea Frilling ${ }^{d}$ Valérie Vilgrain ${ }^{a-c}$ \\ ${ }^{a}$ Department of Radiology, University Hospitals of Beaujon, Clichy, ${ }^{b}$ University Paris Diderot, Sorbonne Paris \\ Cité, and 'INSERM U1149, Centre de Recherche Biomédicale Bichat-Beaujon, CRB3, Paris, France; ${ }^{\mathrm{d}}$ Department of

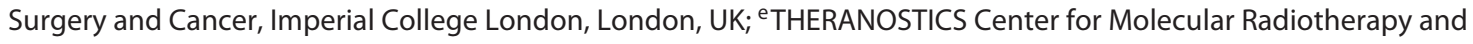 \\ Molecular Imaging, ENETS Center of Excellence, Zentralklinik Bad Berka, Bad Berka, Germany
}

\section{Keywords}

Neuroendocrine liver metastases $\cdot$ Resectability $\cdot$ Computed tomography $\cdot$ Magnetic resonance imaging $\cdot$ Positron emission tomography

\begin{abstract}
This review evaluates the diagnostic efficacy of different morphological and functional imaging modalities (ultrasound [US], computed tomography [CT], magnetic resonance $[M R]$ imaging, scintigraphy, and positron emission tomography [PET]) in detecting neuroendocrine liver metastases (NELM), assessing vascular and biliary involvement, and the presence of extrahepatic disease. MR imaging is superior for depicting NELM compared to US, CT, and somatostatin receptor scintigraphy. Diffusion-weighted MR imaging is more sensitive for detecting NELM than both T2-weighted and dynamic gadolinium-enhanced MR sequences, and should be systematically performed. Similarly, gadoxetic acid-enhanced MR imaging is more sensitive for detecting liver metastases than conventional extracellular gadolinium chelate-enhanced MR sequences. Its role in detecting NELM remains investigational but appears promising. Somatostatin
\end{abstract}

() 2017 S. Karger AG, Basel receptor-targeted PET/CT is a highly effective approach in assessing the resectability of well-differentiated NELM due to very high specificity (and high sensitivity) and its ability to detect small volume extrahepatic disease; this molecular imaging modality is becoming increasingly available in and outside Europe after the recent approval of ${ }^{68} 68$-DOTATATE in the US. In addition, the information from multiphase, contrast-enhanced CT with $3 \mathrm{D}$ reconstruction - obtained concurrently with the information on somatostatin receptor expression of the metastases - is very helpful in planning the extent and type of resection of NELM.

๑) 2017 S. Karger AG, Basel

\section{Introduction}

Neuroendocrine tumors (NET), recently renamed as neuroendocrine neoplasms, predominantly arise within the intestinal tract and pancreas, but may develop in various organs and commonly metastasize to the liver. Due to frequently bilobar and multifocal manifestation of neuroendocrine liver metastases (NELM), not more than $20-30 \%$ of patients are candidates for liver resection with

\section{KARGER}

E-Mail karger@karger.com

www.karger.com/nen
Maxime Ronot, $\mathrm{MD}, \mathrm{PhD}$

Department of Radiology, Beaujon Hospital, AP-HP

100 Boulevard du Général Leclerc

FR-92118 Clichy (France)

E-Mail maxime.ronot@aphp.fr 
curative intent. Surgery has been shown to be the most effective treatment option for the majority of well-differentiated NELM, although it has never been compared to other treatment modalities in a prospective randomized trial [1]. When surgery is considered, the assessment of tumor resectability is mainly based on imaging. Yet, the question of which morphological and functional imaging method(s) should be used to detect liver metastases, and therefore decide if they are amenable for complete resection, has not been extensively discussed. Thus, the aim of this review was to address this hitherto underevaluated but important clinical question.

\section{Background}

Approximately $30-80 \%$ of patients with NET originating from the gastroenteropancreatic system (GEP NET) will develop synchronous or metachronous liver metastases. Hepatic metastases constitute the most important prognostic factor, as historical 5-year overall survival rates are around $50 \%$ for those with, compared to $70-80 \%$ for those without liver involvement [2-5]. Importantly, not only the presence, but also the extent of liver involvement is crucial; it is therefore important to identify the exact number and size of liver metastases, their proximity to vascular and biliary structures, and the volume of the anticipated future liver remnant. Historical data have suggested that the 5-year survival rate in patients with fewer than 5 liver metastases is approximately the same as in those with apparently no metastases (73 vs. $79 \%$ ), whereas those with more than 5 lesions have a 5 -year survival rate of $47 \%$ [6]. Three different morphological patterns of liver infiltration by neuroendocrine metastases have been identified; these have an impact on both the therapeutic approach and overall survival [7]: (a) "simple pattern" is defined as the presence of a single liver metastasis irrespective of the size and location; (b) "complex pattern" defined as the presence of liver metastases with one lobe primarily affected but with smaller satellite lesions in the other; and (c) "diffuse pattern" defined as the presence of multifocal liver metastases. The latter represents $60-70 \%$ of cases, which are not usually surgically treated [7].

It has been suggested that surgical resection can improve prognosis and quality of life in selected cases despite high recurrence rates following resection [8-12]. This is why it is considered the best therapeutic option when possibly achievable, and in fact is the only potentially curative approach. As a consequence, one of the

Assessment of Neuroendocrine Liver

Metastases most important facets of the diagnostic workup in NET patients is to accurately assess the extent of metastatic disease. Several imaging techniques with a broad range of sensitivities and specificities have been employed in this regard based on local availability and expertise [13]. The use of sensitive imaging tools is mandated for the detection of extrahepatic disease for assessing the appropriateness of resection of NELM, i.e. the oncological resectability.

Notably, some patients may undergo surveillance before any treatment decision, and others - typically those with multiple, bilobar liver metastases - may benefit from nonsurgical procedures including somatostatin analogues, liver-directed interventional radiology (percutaneous ablation, or intra-arterial therapies), peptide receptor radionuclide therapy or drugs targeting specific pathways (e.g., mTOR inhibitors) [14-17]. The choice will depend on the tumor burden, the presence or lack of extrahepatic disease, imaging-detectable biological characteristics of tumors (e.g., vascularization, proliferation rate, differentiation, fixation of somatostatin receptor [SSTR]-targeted tracers), and on the performance status of the patient. Clearly, the radiological interrogation of various aspects of tumor biology in individual patients may predict biological behavior and suitability for the aforementioned therapeutic strategies. However, although such imaging is an important aspect of NELM management in general and indeed connected to the assessment of the resectability of NELM, this is outside of the scope of the present review.

\section{Detection of Liver Metastases}

\section{Ultrasound and Contrast-Enhanced Ultrasound}

On ultrasound (US), the appearance of NELM is variable, potentially with hypoechoic, isoechoic, hyperechoic, or heterogeneous with mixed hyper- and hypoechoic patterns. In the series of Mork et al. [18], the latter was the most common pattern and was observed in $61 \%$ of the cases, including some metastases that had a central cystic portion. Less often, NELM may appear hypoechoic (21\%) or hyperechoic (18\%). In another series, the most common pattern of hepatic metastases (48\%, 23/47 patients) was the hypoechoic one [19]. The mixed hyper- and hypoechoic pattern is much more often seen in NELM than in other hepatic secondaries [18]. The central cystic appearance is also highly characteristic of NELM [18]. Hyperechoic metastases should not be confused with hemangiomas, classically described as hyperechoic lesions.

Neuroendocrinology 2018;106:74-88 DOI: $10.1159 / 000479293$ 
However, and importantly, if the latter is true in patients with no history of cancer, and it should be applied with caution in oncological patients.

Another characteristic finding of liver metastases from GEP NET is the hypervascularity on color Doppler imaging, which delineates them (66 vs. 16\%) from liver metastases derived from other malignancies [18]. Similarly, the vast majority of NELM show a pronounced arterial enhancement, either homogeneously or peripherally on contrast-enhanced US (CEUS) using Sonovue (Bracco) (78-86\%), whereas most other liver metastases (82\%) are hypoechoic during the arterial phase $[18,19]$. Interestingly, in the series of Mork et al. [18] diffuse arterial enhancement was never observed in the latter class of lesions. As in other liver metastases, NELM are hypoechoic during the portal venous phase, but this finding is observed in only $40-88.6 \%$ of the cases $[18,19]$. In the delayed phase, most NELM are hypoechoic [19].

NELM often show characteristic findings on conventional US and CEUS. These findings are likely due to the different vascular characteristics when compared to liver metastases of other primaries.

However, confusion of highly vascularized liver metastases with hemangiomas is not uncommon and may delay the diagnosis of a NET significantly. Other imaging techniques, especially magnetic resonance imaging (MRI) should be considered to differentiate between the two $[20,21]$.

The use of contrast-enhanced sonography has been shown to both increase diagnostic confidence and improve the staging of NELM from GEP NET $[19,22]$, as the areas under the receiver operating characteristic curves related to the diagnostic confidence ranged from 0.916 for baseline B-mode sonography to 1.000 for contrast-enhanced sonography in a series of 38 patients with pancreatic NET $(p<0.05)$. All the liver lesions that were correctly classified as metastatic were hypoechoic in the late-phase images [22].

In a series of 30 patients with NET who were prospectively investigated with US, CEUS, and MRI, 17 had a total of 69 hepatic metastases. CEUS improved the detection of individual liver metastases from 47 to $68 \mathrm{com}$ pared to unenhanced ultrasound (Se $68 \%$ vs. $99 \%, p<$ $0.0001)$ [19]. Moreover, CEUS was shown to increase lesion specificity. Two false-positive lesions on conventional ultrasound were correctly classified as benign on CEUS and were confirmed as liver hemangiomas [19].

CEUS depicts significantly more NELM than conventional ultrasound, but it is not part of the clinical practice.

76

Neuroendocrinology 2018;106:74-88 DOI: $10.1159 / 000479293$

\section{Computed Tomography}

In 1987, Wank et al. [23] reported a per-patient sensitivity and specificity of computed tomography (CT) for depicting NELM in a series of 61 patients with ZollingerEllison syndrome of 72 and $98 \%$, respectively. In this series, tumor depiction was related to the size of the lesion: no metastasis smaller than $1 \mathrm{~cm}$ was seen on CT, while most of the metastases larger than $1 \mathrm{~cm}$ were identified ( 3 out of 4 metastases between 1 and $3 \mathrm{~cm}$, and 10 out of 12 metastases larger than $3 \mathrm{~cm}$ ) [23].

Since these early promising results, CT technology has dramatically improved. Initially, it was demonstrated that multiphasic helical CT using a hepatic artery dominant phase acquisition and a portal venous phase acquisition is more efficacious than conventional CT using a single portal venous phase technique in detecting hypervascular hepatic neoplasms, both primary and metastatic $[24,25]$. Subsequently, multirow detector CT scanners have allowed improvements in $z$ axis coverage speed and longitudinal resolution. These improvements translate into rapid hepatic imaging using smaller slice thicknesses [26].

In a series of 6 patients with NET, the arterial CT phase detected a total of 17 liver metastases compared with 9 seen in the portal venous phase [27]. Among the liver metastases, 8 deposits $\leq 5 \mathrm{~mm}$ in size were detected on arterial CT phase, whereas only 3 were seen on portal venous phase [28]. Paulson et al. [29] have evaluated the detection of proven liver metastases from midgut NET on triple-phase helical CT in 31 patients including unenhanced, hepatic arterial-dominant, and portal venous-dominant phases. The mean numbers of liver metastases from the pooled data were 194, 202, and 209 on unenhanced, hepatic arterial-dominant, and portal venous-dominant phases, respectively. The vast majority of liver metastases of midgut NET were shown to be hypoattenuating (91\%) on unenhanced images, whilst the remainder had mixed attenuation. Their appearance was more variable on hepatic arterial-dominant phase: 44 were hyperattenuating, 33 were hypoattenuating, and 24 had mixed attenuation. Most of them (77\%) were hypoattenuating on portal venous-dominant phases, whereas $20 \%$ had mixed attenuation [29]. In $38-50 \%$ of the cases, the portal venous phase was superior to the other phases in terms of the number of lesions counted, whereas in $23-42 \%$ of the cases, the hepatic arterial phase was superior to the other phases [29]. Six (3\%) of these 206 lesions were seen only in the noncontrast phase, 28 (14\%) were seen only in the hepatic arterial phase, and $6(3 \%)$ were seen only in the portal venous phase [29]. In our recent series, we have shown that although most NELM were hypervascular,
Ronot/Clift/Baum/Singh/Kulkarni/ Frilling/Vilgrain 
less than half of them were found to be hypervascular with washout. Moreover, there were significant differences between enteric and pancreatic NELM, as lesions with a pancreatic origin were more frequently isoattenuating on portal venous phase images, while enteric lesions were more frequently typical, and hypoattenuating on portal venous phase images [30].

As most NELM are hypervascular, CT examination must include hepatic arterial phase in patients suspected of having such liver metastases.

\section{Magnetic Resonance Imaging}

The MRI characteristics of NELM have been reported in a relatively limited number of studies [20,31-33]. The early reports showed that most of them were strongly hypointense on T1- and strongly hyperintense on T2weighted sequences and could thus mimic hepatic hemangiomas [20, 31, 32, 34]. For this reason, the usefulness of contrast-enhanced sequences was stressed, and early enhancement and heterogeneity on contrast-enhanced sequences were described as the most common features of these metastases [20]. In addition, 15\% of NELM were seen only on arterial-phase contrast-enhanced images and not on unenhanced MR images [31]. Dromain et al. [32] confirmed these initial data as most metastases were found to be hypointense (93-94\%) on unenhanced T1weighted images and moderately or strongly hyperintense (85-86\%) (close to the signal intensity of fluid) on T2-weighted images: in a series of 37 patients with 359 NELM, most metastases were hyperintense on hepatic arterial phase and portal venous phase images ( 80 and $70 \%$, respectively). In a per-patient analysis, the enhancement pattern was hypervascular in 27 patients (289 metastases), hypovascular in 4 patients (20 metastases), peripheral with progressive fill-in in 4 patients (34 metastases), and delayed in 2 patients ( 6 metastases). The 2 best sequences for detection of NELM were the hepatic arterial phase and the fast spin-echo T2-weighted sequence with fat suppression $(322 / 359,90 \%$, and $279 / 359,78 \%$, respectively). These sequences were significantly better than unenhanced T1-weighted, single-shot fast spin echo T2weighted, and portal venous phase sequences. The superiority of these 2 sequences was also confirmed on a patient-per-patient basis. Lastly, the T2-weighted fast spin-echo pulse sequence with fat suppression showed the greatest lesion-to-liver contrast-to-noise ratio, which was significantly greater than those obtained with unenhanced T1-weighted images, hepatic arterial phase, and portal venous phase images [32].

Assessment of Neuroendocrine Liver

Metastases
On conventional MRI, the combination of hepatic arterial phase and fat-suppressed fast spin-echo T2-weighted images depicts most NELM.

These conventional sequences are nowadays challenged by other sequences such as diffusion-weighted MR (DW-MR) imaging and hepatospecific MR contrast agents.

Several reports have recently shown that DW-MRI improves detection, especially of liver metastases of colorectal origin $[35,36]$. A retrospective study has compared the sensitivity and specificity of DW-MRI for assessing liver metastases from NET with T2-weighted fast spin-echo and 3D dynamic gadolinium-enhanced sequences, using surgical and histopathological findings as the standard of reference [37]. In a series of 162 NELM, it was shown that DW-MR was significantly more sensitive (71-71.6\%) than T2-weighted fast spin-echo (47.5$55.6 \%)$, and dynamic gadolinium-enhanced sequences (48.1-55.6\%) (Fig. 1). The increased sensitivity was also observed in NELM smaller than $1 \mathrm{~cm}$. Interestingly, the specificity of these 3 sequences was similar and ranged from 88.9 to $100 \%$ [37]. Recently, Moryoussef et al. [38] and De Robertis et al. [39] confirmed these results and also showed that DW-MR offered an excellent interreader agreement.

DW-MRI is more sensitive in detecting NELM than T2-weighted fast spin-echo and dynamic gadolinium-enhanced MR sequences and should be systematically performed.

Gadolinium ethoxybenzyl diethylenetriamine pentaacetic acid (gadoxetic acid disodium or Gd-EOB-DTPA; Primovist, Schering, Berlin, Germany) can be used for staging patients with liver metastases, irrespective of the primary tumor origin. Approximately $20 \mathrm{~min}$ after intravenous injection of Gd-EOB-DTPA, normal areas of the liver exhibit $\mathrm{T} 1$ shortening because of specific hepatocyte uptake of approximately $50 \%$ of the injected dose, whereas hepatic metastases do not exhibit $\mathrm{T} 1$ shortening [40]. Combined with the three-dimensional gradientecho sequence technique, which provides excellent spatial resolution, this hepatospecific MR contrast agent is useful in detecting small liver lesions including metastases [41].

A prospective single-institution study, including 55 patients with NELM, compared T2-weighted fast spinecho, DW-MR, and gadoxetic acid-enhanced sequences [42]. The mean numbers of liver metastases were 20.7, 24.0, and 25.7 with T2-weighted fast spin-echo, DW-MR, and gadoxetic acid-enhanced sequences, respectively. However, these results were not statistically significant.

Neuroendocrinology 2018;106:74-88 DOI: $10.1159 / 000479293$ 

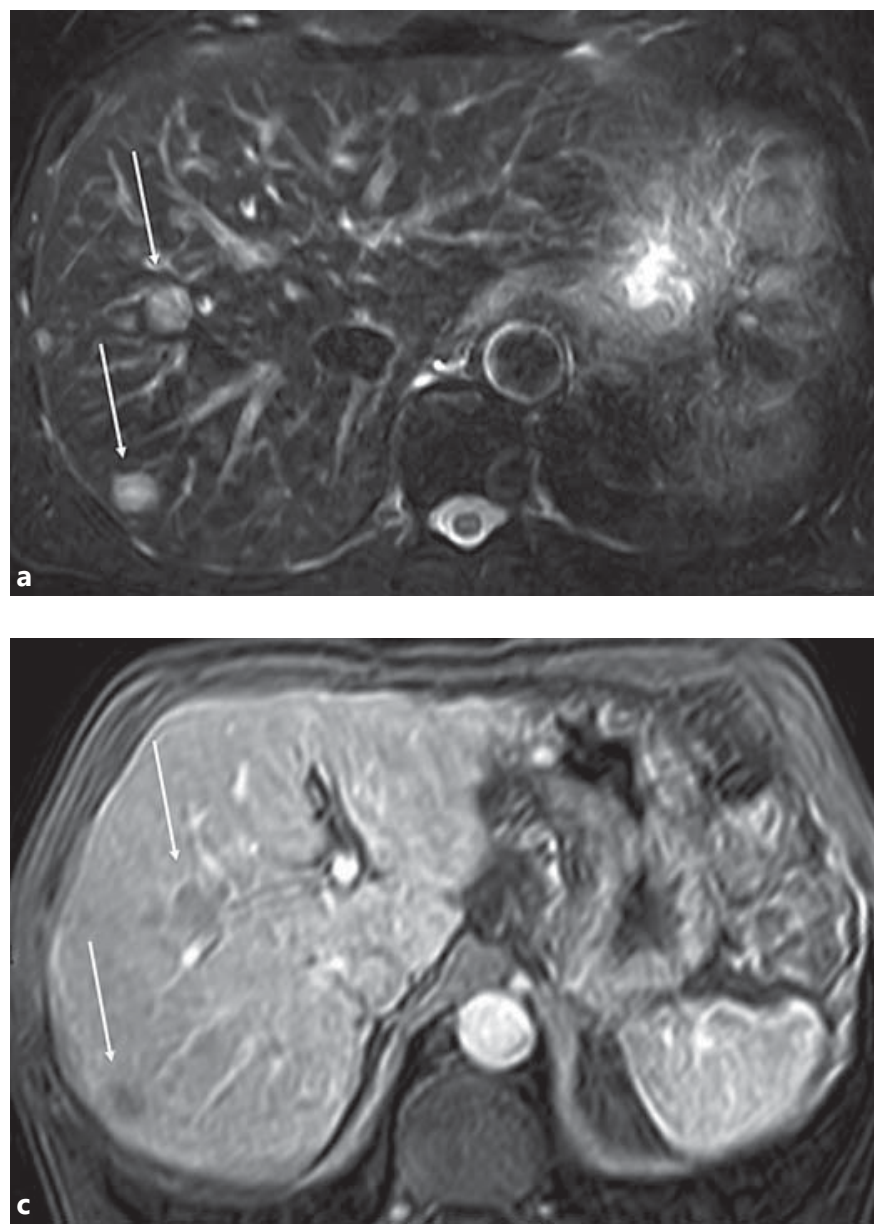

Fig. 1. Transverse MR images obtained in a 55-year-old woman with liver metastases from NET. a On fat-suppressed T2-weighted FSE image, 2 large liver metastases are seen in the right liver lobe (arrows). b, c On postcontrast fat-suppressed three-dimensional spoiled gradient-echo images, these tumors are difficult to see (arrows). They are hypovascular in the arterial phase (b) and slightly
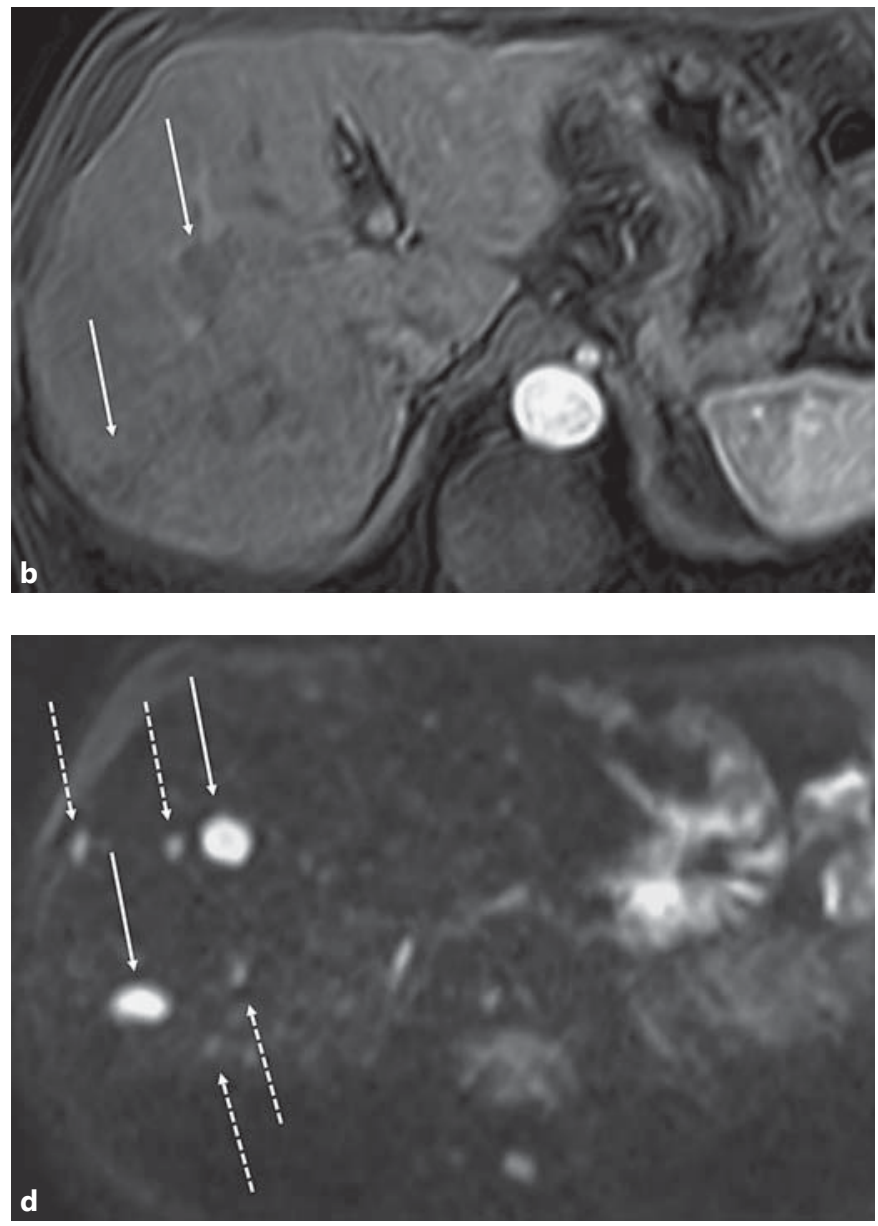

hypointense to liver parenchyma in the portal venous phase (c). d On the DW image $\left(b=600 \mathrm{~s} / \mathrm{mm}^{2}\right)$, the lesions are clearly depicted (arrows) and 4 additional metastases are visible (dashed arrows). Among them, some were retrospectively visible on the T2weighted images. All these metastases were histopathologically confirmed.
While several articles and 1 meta-analysis show that combining DW-MRI with gadoxetic acid-enhanced MRI significantly improves the detection of colorectal liver metastases [43-46], such studies are missing in NET.

Gadoxetic acid-enhanced MRI is in general more sensitive for detecting liver metastases than conventional MR sequences. Its role in detecting NELM is not fully investigated but seems promising.

\section{Comparison and Combination of Imaging Modalities}

Table 1 shows the results of morphological imaging modalities (US, CEUS, CT, and/or MRI) in detecting NELM. Fifteen articles were found addressing this issue, including 8 prospective series [19, 22, 47-57]. The main limitations of these articles were the small patient population and the various methods of reference (i.e., not all histology). Only 3 studies used surgical resection as the method of reference, and only 1 performed anatomical surgical resection [56]. This last study revealed that most NELM were missed on preoperative evaluation. The sensitivities of ultrasound, CT, MR, and SSTR scintigraphy (SRS) were $22 \%$ (60/273), 21.2\% (58/273), 32.6\% (89/273), and $12.4 \%(34 / 273)$, respectively. The accuracies of US, CEUS, CT, MRI, and SRS were 38.4, 38.2, 37.6, 48.8, and $23.9 \%$, respectively, whereas intraoperative examination had an accuracy of $51.9 \%$ [56].
78

Neuroendocrinology 2018;106:74-88 DOI: $10.1159 / 000479293$
Ronot/Clift/Baum/Singh/Kulkarni/ Frilling/Vilgrain 
When using surgical resection and histopathological examination as the method of reference, many NELM are missed on preoperative imaging and intraoperative assessment.

Table 1 demonstrates the results of MRI in detecting NELM. Five studies compared CT and MRI in per-lesion analyses and all showed an increased sensitivity with MRI. In all studies but one, which compared per patient analysis between CT and MRI, MR was superior to CT. The other study was performed in the early 1990s [48]. Schraml et al. [58] also suggested that whole-body MRI was superior to ${ }^{68} \mathrm{Ga}$-DOTATOC multiphase positron emission tomography (PET)/CT for the detection of liver metastases.

MRI is a more accurate imaging modality for NELM depiction compared to ultrasound and CT.

\section{Metabolic, Molecular, and Functional Imaging}

The vast majority of GEP NET express SSTRs, most commonly SSTR2, on their cell membrane, allowing for molecular/functional imaging with radiolabeled somatostatin agonists or antagonists. In the early 1990s, a radiolabeled version of octreotide, Indium-111-DTPADPhe1-octreotide ( ${ }^{111}$ In-octreotide), was introduced as the first SSTR agent and showed affinity to subtypes 2 and 5. For ${ }^{111}$ In-octreoscan, a mean sensitivity of $65 \pm 13 \%$ (range $39-93 \%$ ) and a mean specificity of $76 \pm 11 \%$ have been observed [59], yet it is inferior to both CT and MRI [52] predominantly due to its lack of resolution of subcentimeter lesions.

99mTc-EDDA-HYNIC-TOC (and -TATE) has been shown in a large patient population to be superior to ${ }^{111}$ In-pentetreotide for the detection of SSTR-positive tumors and metastases. [ ${ }^{99 \mathrm{~m}} \mathrm{Tc}$-ethylenediamine- $\mathrm{N}, \mathrm{N}^{\prime}$ diacetic acid (EDDA)//HYNIC, Tyr3] octreotide ( ${ }^{99 \mathrm{~m}} \mathrm{Tc}$ EDDA/HYNIC-TOC; Tektrotyd) is now available (approved radiopharmaceutical by EMA in 2016) in a number of European countries and beyond [60]. The mean sensitivity and specificity for ${ }^{99 \mathrm{~m}} \mathrm{Tc}$-labeled octreotide is $85 \pm 6 \%$ (range $79-94 \%$ ) and $94 \pm 3 \%$, respectively [61]. Iodine-123 metaiodobenzylguanidine ( $\left.{ }^{123} \mathrm{I}-\mathrm{MIBG}\right)$ has also been used in the detection of NET. However, it has been shown to have a lower sensitivity ( $49 \%$ compared with 91\%) compared to ${ }^{111}$ In-octreotide [62].

$\mathrm{PET} / \mathrm{CT}$ imaging revolutionized the management of oncological patients by improving resolution down to $5 \mathrm{~mm}$, enabling the detection of smaller lesions and providing synchronized CT for accurate localization. Fluorine-18 fluorodeoxyglucose $\left({ }^{18} \mathrm{~F}-\mathrm{FDG}\right)$, with avidity to highly metabolically active tumors, has been applied for

Assessment of Neuroendocrine Liver Metastases the detection of NET, but its use is typically limited to higher-grade tumors that are in general more aggressive [63]. Wider utilization of ${ }^{18} \mathrm{~F}$-FDG PET has been suggested on the basis of its prognostication abilities in studies of patients with NET of varying grades [64-66], and recent retrospective reports have suggested that dual ${ }^{18} \mathrm{~F}$-FDG $\mathrm{PET} / \mathrm{CT}$ and SSTR-PET/CT may be predictive for overall survival [67]. However, the ramifications of identifying individual patients with low-grade tumors that are more likely to progress on surgical strategy for NELM are yet to be elucidated. The addition of ${ }^{18} \mathrm{~F}-\mathrm{FDG}$ PET to ${ }^{68} \mathrm{Ga}-\mathrm{DO}-$ TA PET may be useful in patients with initially low-grade NET exhibiting aggressive behavior during the course of the disease as this could theoretically identify if the tumor is de-differentiating.

Analysis of data regarding ${ }^{18} \mathrm{~F}-\mathrm{FDG}$ PET/CT reveals a mean sensitivity of $52 \pm 4 \%$ (ranging from $43-63 \%$ ) and a specificity of $74 \pm 5 \%$ (ranging from $68-82 \%$ ), when analyzing all grades of NET (differentiated and undifferentiated) $[64,68]$. With ${ }^{18} \mathrm{~F}-\mathrm{DOPA}$, the mean sensitivity is $56 \pm 12 \%$ and the mean specificity is $83 \pm 7 \%$, whereas ${ }^{123}$ I-MIBG has a mean sensitivity of $46 \pm 17 \%$ (range 3368\%) [69].

Fluorine-18-L-3,4-dihydroxyphenylalanine $\left({ }^{18} \mathrm{~F}-\mathrm{DO}-\right.$ PA) has been used in well-differentiated, hormone-producing NET based on its role in dopamine synthesis pathways with uptake proportional to tumor cell metabolism [70]. Carbon-11-hydroxytryptophan $\left({ }^{11} \mathrm{C}-5-\mathrm{HTP}\right)$ targets the serotonin production pathway [71]. Unfortunately the short half-life of ${ }^{11} \mathrm{C}(20 \mathrm{~min})$ restricts its use to facilities with an in-house cyclotron. PET radiotracers targeting neuroendocrine cell amine synthesis pathways or alternative cell membrane-bound receptors such as GLP-1R are also in (albeit limited) clinical use, although clearly their role in the evaluation of liver metastases has not been evaluated and can thus not be recommended.

A major breakthrough in PET/CT imaging of NET was the clinical introduction of Gallium-68 labeled peptides in 2001. In addition to the high resolution of PET imaging, this method benefits from a long shelf half-life of the ${ }^{68} \mathrm{Ge} /{ }^{68} \mathrm{Ga}$ generator (270 days) and the introduction of a new binding ligand (DOTA) as well as somatostatin agonists with very high binding affinity to SSTRs. This carries great significance and proved that early imaging with ${ }^{68} \mathrm{Ga}$-peptides has a major impact on staging and the consequent clinical management of NET. The ${ }^{68} \mathrm{Ga}-$ conjugated somatostatin analogues $\left({ }^{68} \mathrm{Ga}\right.$-SSAs) include ${ }^{68} \mathrm{Ga}$-DOTATATE, ${ }^{68} \mathrm{Ga}$-DOTATOC, ${ }^{68} \mathrm{Ga}$-DOTANOC, and others. Studies examining ${ }^{68} \mathrm{Ga}$-somatostatin receptor PET/CT report a mean sensitivity of $94 \pm 3 \%$ (range

Neuroendocrinology 2018;106:74-88 DOI: $10.1159 / 000479293$ 


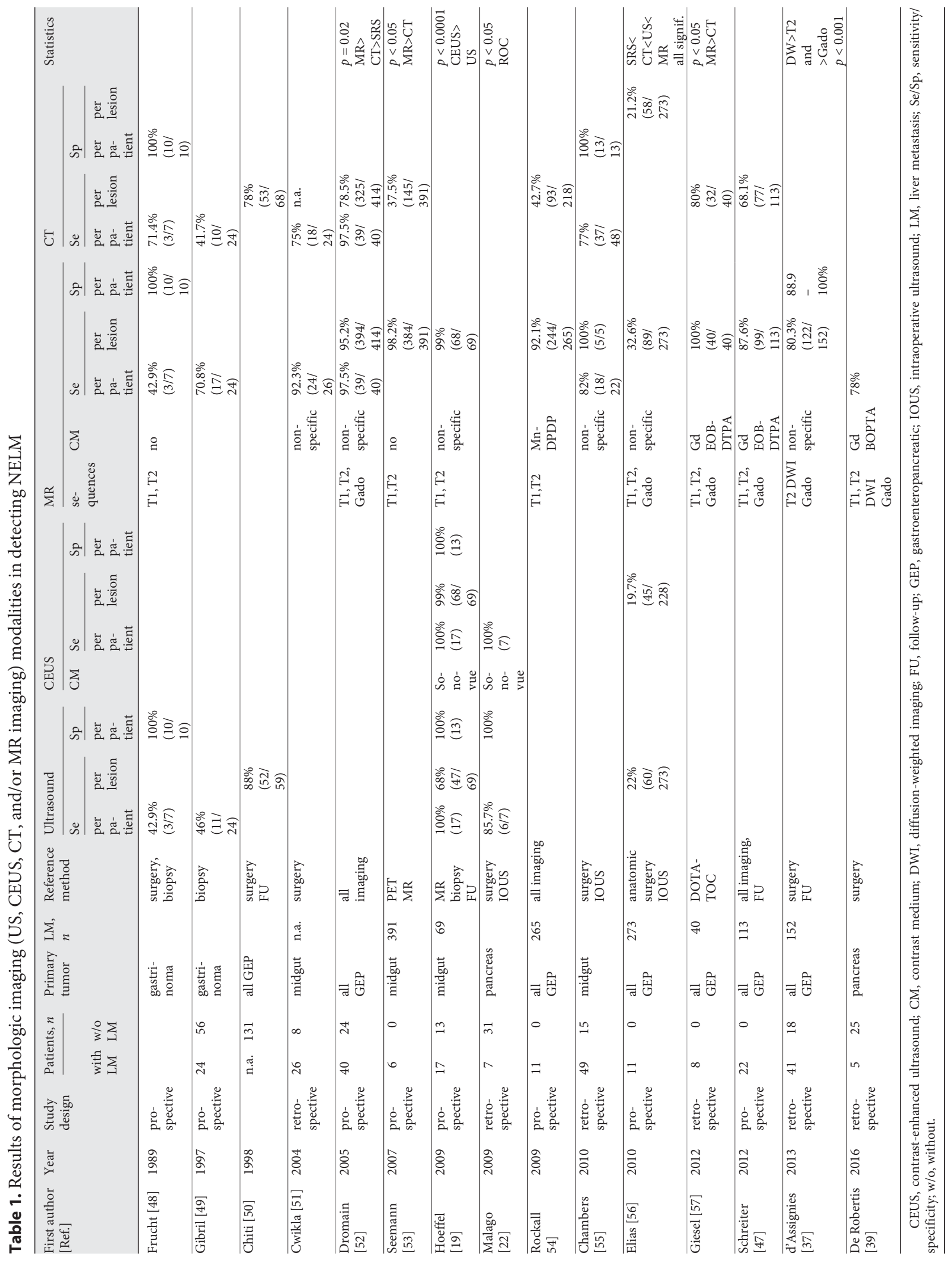



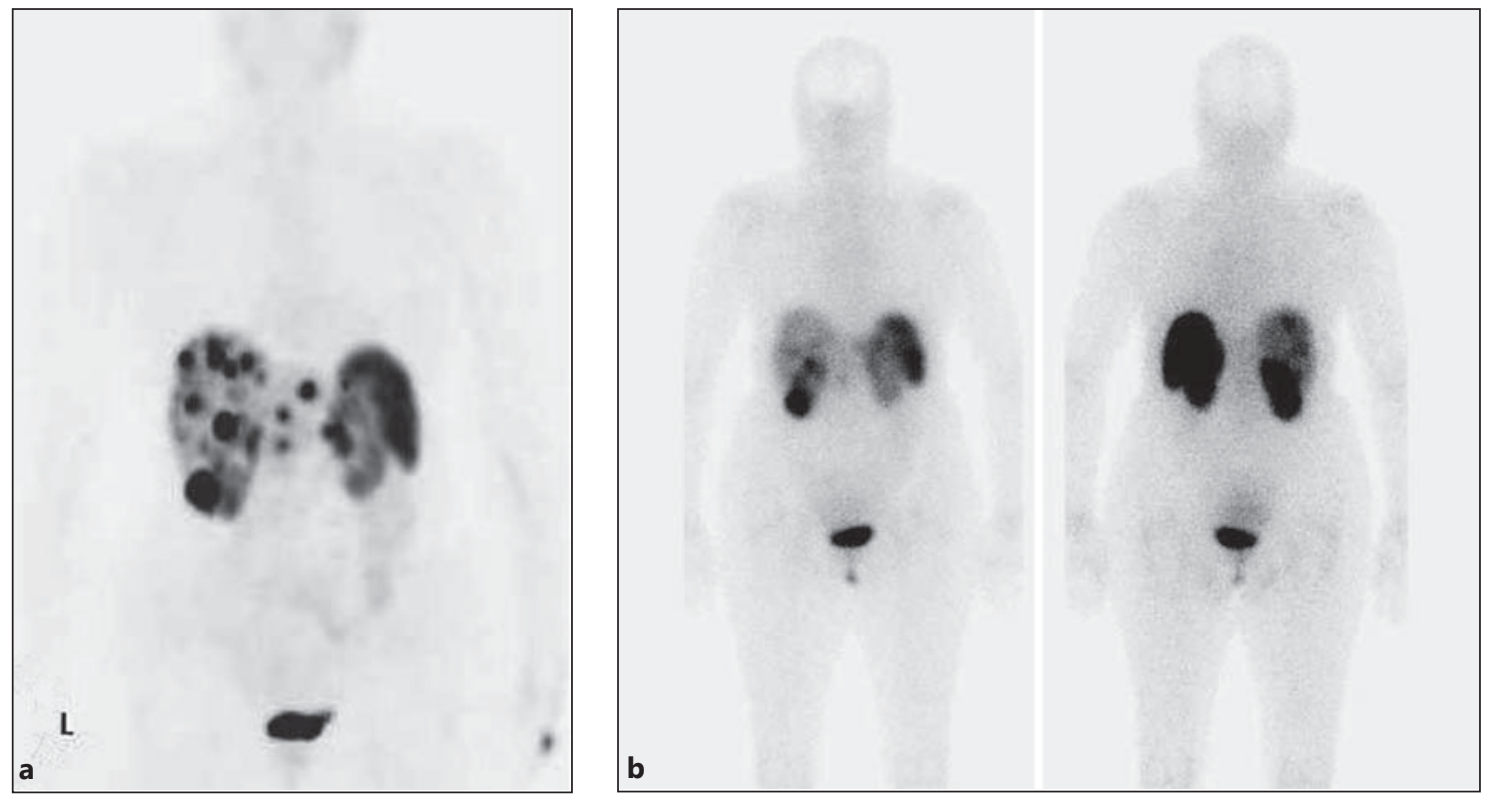

Fig. 2. Example of increased sensitivity of ${ }^{68} \mathrm{Ga}$-DOTATATE PET/CT over ${ }^{111} \mathrm{In}$-octreotide scintigraphy in a patient with nonfunctioning pancreatic NET. ${ }^{68} \mathrm{Ga}$-DOTATATE (a) showed significantly more liver metastases than ${ }^{111}$ In-octreoscan (b).

$82-100 \%)$ and a specificity of $89 \pm 6 \%$ range $(67-100 \%)$ for liver metastases $[72,73]$. Furthermore, the technique is capable of detecting tumor deposits not observed on morphological imaging in up to two-thirds of cases [1].

Recently, SSTR antagonists have been clinically introduced [74] and first phase 1/2 clinical studies show that ${ }^{68} \mathrm{Ga}$-labeled SSTR antagonists are twice as accurate as the agonist ${ }^{68} \mathrm{Ga}$-DOTATOC for detecting liver metastases in GEP NET patients which is mainly attributable to the favorable biodistribution and improved image contrast.

Until recently, the commonest SSTR-targeting technique was SRS with ${ }^{111}$ In-octreotide (OctreoScan); however this tracer has now been superseded by SSTR-targeted PET/CT (Fig. 2). The clinical consequences of incorporating metabolic and functional imaging with PET/CT into radiological workup are tangibly important. The study of Frilling et al. [72] examined the effects on patient management of including ${ }^{68} \mathrm{Ga}$-DOTATOC PET/CT in diagnostic imaging for 52 patients with NET. Herein, ${ }^{68} \mathrm{Ga}$-SSA PET identified additional LM and/or extrahepatic disease undetected by CT or MRI in 22 of the 33 patients with LM. Additionally, it altered management strategies in $60 \%$ of all patients, including cancellation of planned liver resection in 13 patients due to the identification of unresectable extrahepatic disease, and modifi- cation of initially planned surgical approach for 7 patients (Fig. 3).

A recent systematic review and meta-analysis (screening 2,479 articles) comparing ${ }^{68} \mathrm{Ga}$-DOTATATE PET/CT with ${ }^{111}$ In-octreotide and conventional imaging for diagnosis and staging of NET supports the superiority of ${ }^{68} \mathrm{Ga}$-DOTATATE PET/CT for diagnosis or reassessment of tumors with high SSTR expression [75]. Additionally, ${ }^{68} \mathrm{Ga}$-DOTATATE PET/CT provides lower effective radiation dose, superior image quality, and greater patient convenience via a shorter examination time than ${ }^{111}$ In-DTPA-octreotide imaging and therefore should be used where available.

Armbruster et al. [76] compared the accuracy of dynamic contrast-enhanced (DCE) MRI with both ${ }^{18} \mathrm{~F}$-FDGand ${ }^{68} \mathrm{Ga}$-DOTATATE-PET/CT in the detection of NELM by determining the area under the curve (AUC) for the differentiation between metastases and liver background. The SUVmean (mean standardized uptake value) derived from ${ }^{68} \mathrm{Ga}$-DOTATATE- (AUC $\left.=0.966\right)$, and ${ }^{18} \mathrm{~F}-\mathrm{FDG}$ $\mathrm{PET} / \mathrm{CT}(\mathrm{AUC}=0.989)$ revealed higher AUC than the DCE-MRI parameters, arterial flow fraction and intracellular uptake fraction $(\mathrm{AUC}=0.826$, AUC $=0.819$, respectively). The combination of DCE-MRI and PET/CT parameters resulted in the highest AUC, demonstrating that both modalities provide complementary information. 


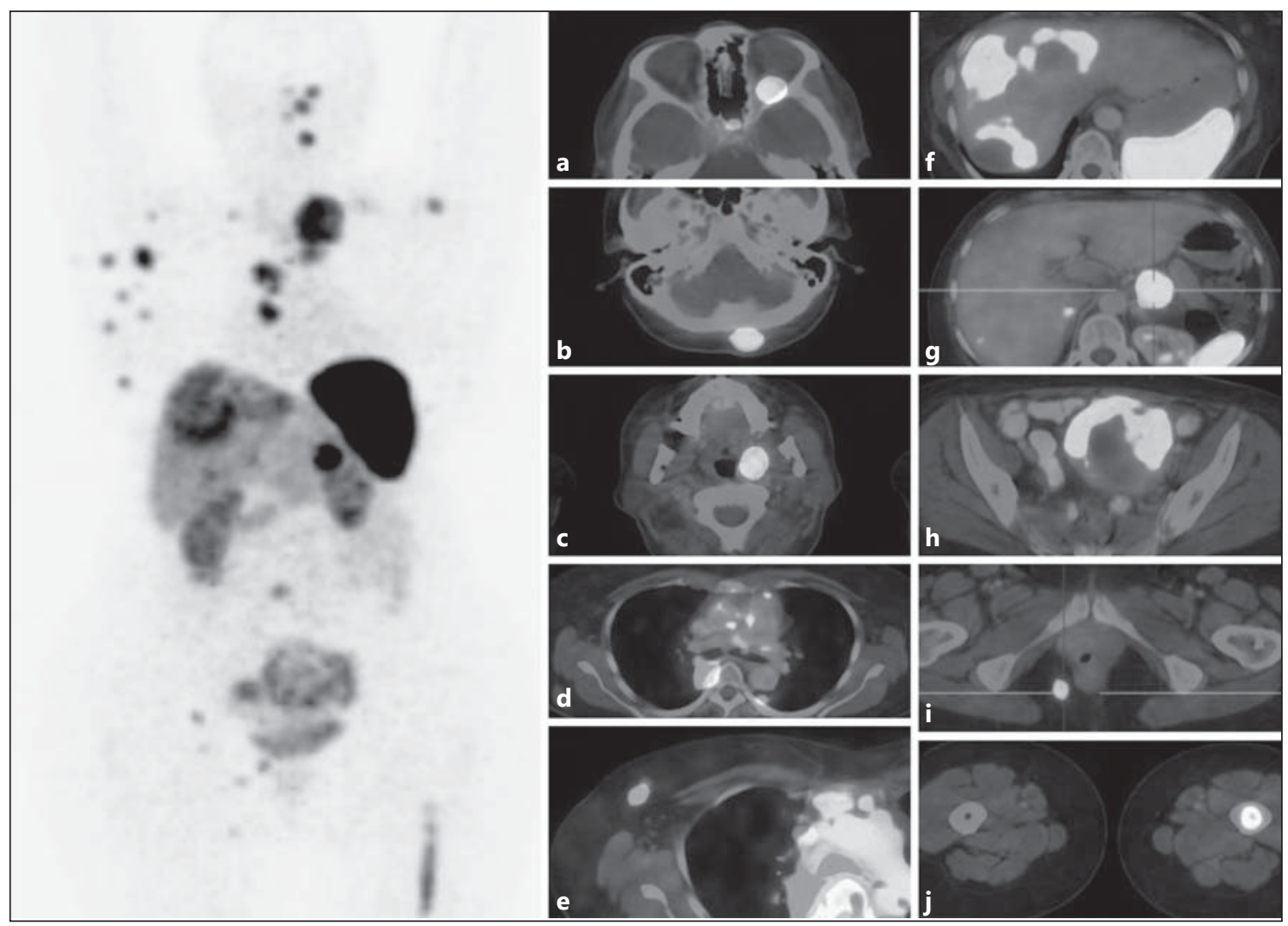

Fig. 3. Patient presenting with a neuroendocrine neoplasm in the pancreatic tail and known liver metastases considered for surgery. ${ }^{68} \mathrm{Ga}$-DOTATOC PET/CT demonstrated multiple, and previously unknown SMS-R positive metastases at the following sites: retroocular (a), soft tissue (galea) (b), cervical lymph node (c), soft tissue and paravertebral lesions (d), right breast (e), liver (f), left gastric lymph node (g), uterus (h), right pararectal soft tissue (i), and bone marrow left femur $(\mathbf{j})$.

PET with radiolabeled somatostatin analogues is a practical, highly accurate functional imaging procedure (and the modality of choice) to assess the resectability of liver metastases in well-differentiated NET. ${ }^{18} \mathrm{~F}$-FDG PET/CT is the functional imaging modality of choice in higher grade and/or poorly differentiated NET.

Experience with other tracers, such as the recently developed ${ }^{64} \mathrm{Cu}$-DOTATATE is limited; however, promising reports have demonstrated its superior ability in detecting NELM relative to CT and SRS [77]. In a comparative analysis of ${ }^{64} \mathrm{Cu}$-DOTATATE and ${ }^{68} \mathrm{Ga}$-DOTATOC PET/CT in 59 patients, there were no significant differences between the numbers of detected liver metastases, although the $>24$-h shelf-life and scanning window of at least $3 \mathrm{~h}$ have been posited as benefits of the former [78]. Furthermore, recent studies of ${ }^{68} \mathrm{Ga}$-SSA PET combined with MRI have been extremely encouraging, yet more research is required in this area before routine implementation is warranted [76]. In NET patients with inconclusive imaging or a lack of visualization with SSTR- targeted modalities, radiotracers targeting neuroendocrine amine metabolism have emerged as promising alternative options, namely ${ }^{18} \mathrm{~F}$-DOPA and ${ }^{11} \mathrm{C}-5$-HTP. $\mathrm{PET} / \mathrm{CT}$ using the former appears to be probably more sensitive than the latter for detecting LM from functionally active, serotonin-producing enteric NET in some patients, whereas the converse is apparent for LM from pancreatic NET.

\section{Detection of Vascular and Biliary Invasion}

Despite extensive literature search, we have not been able to find a definitive answer to the question of which modality best detects vascular and biliary invasion. Notably, NELM are in general well-circumscribed nodular lesions, in contrast to other liver metastases which are more lobulated. This may explain why vascular and biliary invasion is seldom evident on preoperative imaging. Nev- 
ertheless, CT and MRI should be the best imaging modalities in preoperatively detecting vascular and biliary invasion.

Preoperative 3D CT-assisted surgical planning and 3D CT-guided intraoperative navigation have been shown to be helpful in patients considered for complex resection strategies [79]. Its main advantages are the individualized inflow/outflow virtual analyses and the accurate determination of safely perfused/drained retained liver volumes. In a prospective study of 202 consecutive patients with various liver tumors who underwent advanced surgical procedures, 3D CT computer-assisted surgical planning either changed the 2D conventional CT based strategy or provided an entirely different approach in 33\% of instances. As most surgical candidates with liver metastases from GEP NET have bilobar spread of disease, surgical procedures are often complex and may benefit from this technique [80].

Combination of preoperative imaging modalities with intraoperative ultrasound including color Doppler scanning is meaningful, especially when addressing hepatic vein landmarks for the determination of the resection line. The bimodal ascertainment of this important operative facet provides the surgeon with additional confidence during the surgical procedure as preservation of hepatic veins in turn helps to preserve the drainage and thus function of the liver remnant [81].

\section{Detection of Extrahepatic Disease}

The prevalence of extrahepatic disease is very different in patients with small bowel or pancreatic NET; while the latter mainly present with peripancreatic lymph node metastases, metastatic spread to mesentery including the mesenteric root is a hallmark of small intestine NET. Bone metastases are seen in both tumor entities. Ultrasound, CT, and MRI provide useful information, with variable performance, depending on the metastatic site. Yet, the power of ${ }^{68} \mathrm{Ga}$-SSA PET/CT over morphological imaging in assessing the oncological resectability of NELM depends also on its increased ability to detect extrahepatic (especially skeletal) metastases [82, 83]. Of note, the impact of small volume bone disease - frequently detected with modern technology - on the biological course of neuroendocrine disease remains unclear. Molecular imaging with such radiotracers is highly sensitive and enables the obtainment of high-quality images capable of detecting lesions outside the abdomen with high interobserver reproducibility [84]. Indeed, ${ }^{68} \mathrm{Ga}-$

Assessment of Neuroendocrine Liver Metastases
DOTATOC PET/CT has the highest mean sensitivity of $90 \pm 4 \%$ (range $85-100 \%$ ) and a high specificity of $79 \pm$ $5 \%$ (67-97\%) for detection of extrahepatic metastases [73, $82,83,85]$. The sensitivity of ${ }^{111}$ In-octreoscan for metastases outside the liver varies widely from $22 \%$ (skeletal metastases) to $90 \%[86,87]$.

Patients with pancreatic or small bowel NET often present at a late stage of the disease with metastases to regional lymph nodes, the liver, or peritoneum occurring in up to $90 \%$ of patients at the time of initial assessment [88, 89]. Resection of the primary tumor and locoregional nodal disease in the presence of nonresectable LM is effective in relieving local symptoms frequently seen in these setting; however, its effect on overall survival needs further assessment [88, 90-93].

Mesenteric disease can form large masses within the small bowel mesentery, which are frequently accompanied by desmoplastic reactions and fibrosis in surrounding tissues in a characteristic "spoke wheel" appearance $[55,94,95]$. Masses usually arise within the fat or nodal tissue of the small bowel mesentery, although the exact nidus of metastatic tumor growth in the mesentery is often not certain. On CT, they appear as an ill-defined mesenteric mass containing calcification in up to $70 \%$ of cases [96]. The mesenteric mass may appear to be spiculated with a stellate pattern. Occasionally, the tumor may appear cystic [97]. The size of the mass can vary from $1 \mathrm{~cm}$ or less to several centimeters, and due to the mesenteric fibrosis and desmoplastic reaction, the mesenteric vessels may be involved. Multiplanar reconstructions and threedimensional CT angiography might be useful for surgical planning [97]. Thickening and ischemia of the involved small-bowel loops may also be seen as a result of mesenteric vessel encasement [97]. On MR images, the mesenteric metastases appear as nodular, spiculated lesions with an isointense signal on T1- and T2-weighted images [31]. On postcontrast T1-weighted images, they enhance homogeneously. Associated adjacent mesentery stranding - seen as thin, hypointense strands on T1- and T2weighted images - is often seen [31].

In 64 patients with NET of the small bowel, mesenteric metastases were seen on imaging in $47(73 \%)$ and were present at laparotomy in $56(88 \%)$ patients [55]. Twelve patients of this series ( $21 \%$ of patients with nodal metastases) had mesenteric metastatic lesions that could not be completely resected because of invasion of, or close proximity to the superior mesenteric vessels. In 9 of these 12 patients, preoperative imaging with $\mathrm{CT}$ and/or MR suggested the involvement or close proximity of the superior mesenteric vessels to the mesenteric metastases

Neuroendocrinology 2018;106:74-88 DOI: $10.1159 / 000479293$ 
[55]. In another series [51] including 34 patients with small bowel NET, 18 had positive lymph nodes and MRI identified metastatic lymph nodes in 11 of them (61\%). Metastatic lymph nodes seen in the distal mesentery allow in general for complete resection of the locoregional disease. Those situated on the level of the mesenteric root require more extensive surgery or may even be not amenable to conventional surgical techniques [98]. As small bowel-sparing surgery is a crucial issue, some groups have proposed a preoperative CT classification of mesenteric lymph nodes that aids standardization of the surgical management of those patients [99]. It must be also stressed that due to its high sensitivity and specificity, ${ }^{68} \mathrm{Ga}-\mathrm{SSA}$ $\mathrm{PET} / \mathrm{CT}$ accurately localizes primary NET and metastatic mesenteric lymph nodes, making radioguided surgery feasible.

Seeman [53] evaluated low-dose CT, contrast-enhanced CT at the portal phase, PET, and combined PET/ CT. The author showed a low sensitivity of low-dose CT compared to CE-CT for lymph node depiction (25.4 vs. $64.8 \%)$. PET imaging was superior to CT and the best combination was PET and CE-CT. The role of MRI and PET/MRI has also been evaluated for lymph node metastases, demonstrating that CT was superior to MR and PET/CT to PET/MRI [100]. In another series of 27 NET (mostly of small bowel origin), multidetector contrastenhanced CT was more sensitive than SRS for detecting extrahepatic metastases [101]. The lesions that were not detected by SRS were retroperitoneal lymphadenopathy, bone metastasis, peritoneal implants, lung metastasis, and mediastinal lymphadenopathy. More recent data have demonstrated that whilst ${ }^{68} \mathrm{Ga}$-SSA PET/CT may identify additional lesions undetectable by CT and MRI in the preoperative staging of small bowel NET, all imaging modality classes are hindered by their limited capability in depicting lesions smaller than $1 \mathrm{~cm}$ in size, notably miliary liver metastases and multifocal primary tumors; indeed, meticulous intraoperative exploration may be superior to radiological preoperative imaging in assessing true disease extent [89].

Peritoneal disease in patients with small bowel NET is reported in $20-33 \%$ of surgical cases [102, 103]. The prognostic significance of peritoneal metastatic disease from NET and the optimal management of this entity remain uncertain [102-104]. On CT, peritoneal metastases present as multiple peritoneal implants. On MRI, they demonstrate intermediate signal intensity on T1-weighted images and an intermediate signal or moderately high signal on T2-weighted images [31]. These peritoneal implants are hypervascular, showing moderate to intense enhancement on early postcontrast images and decreased enhancement on late postcontrast images [31]. In one study [55], peritoneal metastases were seen on preoperative imaging in 4 patients (6\%) and found at laparotomy in 16 patients (25\%). Recently, Moryoussef et al. [38] suggested that whole-body diffusion-weighted imaging may identify more lesions than conventional whole-body MRI sequences.

Besides liver metastases, the most common metastatic site of small bowel NET are mesenteric lymph nodes. Encasement of the mesenteric root or close proximity to the superior mesenteric vessels may preclude standard surgical resection. CT and MRI are helpful to assess resectability, but may understage local extension. SSTR-targeted PET/CT detects lesions that CT and MRI cannot depict, and therefore offers in addition to preoperative imaging, the prospect of radioguided surgery as a potentially useful option for small primaries and locoregional lymph node metastases. Yet, all modalities are limited in terms of identifying disease deposits smaller than $5 \mathrm{~mm}$.

The role of imaging in assessing extrahepatic involvement in pancreatic NET has been less extensively studied than in small bowel tumors. In a series of 131 pancreatic NET, the sensitivity of CT and ultrasound for detecting extrahepatic metastases was 23/35 (66\%) and 15/32 (47\%), respectively while specificity of CT and ultrasound was 98 and $100 \%$ [50]. Nodal metastases can be seen on contrast-enhanced CT and MR [34]. They are usually more conspicuous on the arterial phase than the portal venous phase [28]. They are mostly seen in periceliac, mesenteric, portocaval, aortocaval, and retrocaval sites.

Peripancreatic vascular involvement can be seen, although it occurs less often than in pancreatic adenocarcinoma. Contrast-enhanced CT and MRI are the key imaging modalities. Arterial encasement is more readily visible on the arterial phase, and venous involvement (superior mesenteric vein, portal vein, and splenic vein) is better evaluated in the portal venous phase [28]. Although uncommon, enhancing tumor thrombus in the splenic, mesenteric or portal vein is highly specific for NET $[28,33]$.

Pancreatic NET may extend to peripancreatic vessels and regional lymph nodes. Vascular assessment is best performed with CT or MRI. Combined morphological and functional imaging should be proposed for depicting nodal metastases. In addition to morphological and functional imaging, endoscopically guided ultrasonography (in combination with fine needle aspiration biopsy) has an important role in assessing of pancreatic tumors.
84

Neuroendocrinology 2018;106:74-88 DOI: $10.1159 / 000479293$
Ronot/Clift/Baum/Singh/Kulkarni/ Frilling/Vilgrain 


\section{Conclusion: What Imaging Workup Should Be Done?}

In conclusion, and based on the evidence discussed above, we would like to propose the following practical recommendations for the radiological workup of NELM in order to identify patients suitable for treatment with curative intent:

- Initial workup should include contrast-enhanced whole body CT to evaluate the liver burden, classify patients with regard to their liver infiltration pattern, and detect extrahepatic disease. At this point, the patient should be discussed in a multidisciplinary team setting to assess the possibility of liver resection.

- If the patient is considered for hepatic resection, liver MRI including diffusion-weighted imaging and injec- tion of hepatospecific contrast medium should be performed to better evaluate the extent of liver disease. Metabolic imaging with ${ }^{68} \mathrm{Ga}$-SSA PET/CT should also be performed with a primary aim to detect extrahepatic disease.

- If resectability is not identified as being attainable, treatment decisions will rely mainly on CT and functional/metabolic imaging (details are beyond the scope of this article).

- Follow-up imaging strategy depends on the pursued treatment pathway. Patients who underwent liver resection should be ideally followed by MRI, although contrast-enhanced CT is still first-line examination in daily practice. Metabolic imaging is useful in cases where morphological imaging indicates recurrence.

\section{References}

1 Frilling A, Modlin IM, Kidd M, Russell C, Breitenstein S, Salem R, Kwekkeboom D, Lau WY, Klersy C, Vilgrain V, Davidson B, Siegler M, Caplin M, Solcia E, Schilsky R; Working Group on Neuroendocrine Liver Metastases: Recommendations for management of patients with neuroendocrine liver metastases. Lancet Oncol 2014;15:e8-e21.

2 Scigliano S, Lebtahi R, Maire F, Stievenart JL, Kianmanesh R, Sauvanet A, Vullierme MP, Couvelard A, Belghiti J, Ruszniewski P, Le Guludec D: Clinical and imaging follow-up after exhaustive liver resection of endocrine metastases: a 15-year monocentric experience. Endocr Relat Cancer 2009;16:977-990.

3 Pavel M, O’Toole D, Costa F, Capdevila J, Gross D, Kianmanesh R, Krenning E, Knigge U, Salazar R, Pape UF, Oberg K; Vienna Consensus Conference participants: ENETS consensus guidelines update for the management of distant metastatic disease of intestinal, pancreatic, bronchial neuroendocrine neoplasms (NEN) and NEN of unknown primary site. Neuroendocrinology 2016;103:172-185.

4 Durante C, Boukheris H, Dromain C, Duvillard P, Leboulleux S, Elias D, de Baere T, Malka D, Lumbroso J, Guigay J, Schlumberger M, Ducreux M, Baudin E: Prognostic factors influencing survival from metastatic (stage IV) gastroenteropancreatic well-differentiated endocrine carcinoma. Endocr Relat Cancer 2009;16:585-597.

5 Palazzo M, Lombard-Bohas C, Cadiot G, Matysiak-Budnik T, Rebours V, Vullierme MP, Couvelard A, Hentic O, Ruszniewski P: Ki67 proliferation index, hepatic tumor load, and pretreatment tumor growth predict the antitumoral efficacy of lanreotide in patients with malignant digestive neuroendocrine tumors. Eur J Gastroenterol Hepatol 2013;25:232238.
6 Janson ET, Holmberg L, Stridsberg M, Eriksson B, Theodorsson E, Wilander E, Oberg K: Carcinoid tumors: analysis of prognostic factors and survival in 301 patients from a referral center. Ann Oncol 1997;8:685-690.

7 Frilling A, Li J, Malamutmann E, Schmid KW, Bockisch A, Broelsch CE: Treatment of liver metastases from neuroendocrine tumours in relation to the extent of hepatic disease. Br J Surg 2009;96:175-184.

8 Sarmiento JM, Heywood G, Rubin J, Ilstrup DM, Nagorney DM, Que FG: Surgical treatment of neuroendocrine metastases to the liver: a plea for resection to increase survival. J Am Coll Surg 2003;197:29-37.

9 Sarmiento JM, Que FG: Hepatic surgery for metastases from neuroendocrine tumors. Surg Oncol Clin N Am 2003;12:231-242.

10 Elias D, Lasser P, Ducreux M, Duvillard P, Ouellet JF, Dromain C, Schlumberger M, Pocard M, Boige V, Miquel C, Baudin E: Liver resection (and associated extrahepatic resections) for metastatic well-differentiated endocrine tumors: a 15-year single center prospective study. Surgery 2003;133:375382.

11 Chamberlain RS, Canes D, Brown KT, Saltz L, Jarnagin W, Fong Y, Blumgart LH: Hepatic neuroendocrine metastases: does intervention alter outcomes? J Am Coll Surg 2000;190: 432-445.

12 Mayo SC, de Jong MC, Pulitano C, Clary BM, Reddy SK, Gamblin TC, Celinksi SA, Kooby DA, Staley CA, Stokes JB, Chu CK, Ferrero A, Schulick RD, Choti MA, Mentha G, Strub J, Bauer TW, Adams RB, Aldrighetti L, Capussotti L, Pawlik TM: Surgical management of hepatic neuroendocrine tumor metastasis: results from an international multi-institutional analysis. Ann Surg Oncol 2010;17:31293136.
13 Baumann T, Rottenburger C, Nicolas G, Wild D: Gastroenteropancreatic neuroendocrine tumours (GEP-NET) - imaging and staging. Best Pract Res Clin Endocrinol Metab 2016; 30:45-57.

14 Caplin ME, Pavel M, Cwikla JB, Phan AT, et al: Anti-tumour effects of lanreotide for pancreatic and intestinal neuroendocrine tumours: the CLARINET open-label extension study. Endocr Relat Cancer 2016;23:191-199.

15 Strosberg J, El-Haddad G, Wolin E, Hendifar A, et al: Phase 3 trial of $177 \mathrm{Lu}$-Dotatate for midgut neuroendocrine tumors. $\mathrm{N}$ Engl J Med 2017;376:125-135.

16 Pavel ME, Hainsworth JD, Baudin E, Peeters $M$, et al: Everolimus plus octreotide long-acting repeatable for the treatment of advanced neuroendocrine tumours associated with carcinoid syndrome (RADIANT-2): a randomised, placebo-controlled, phase 3 study. Lancet 2011;378:2005-2012.

17 Raymond E, Dahan L, Raoul JL, Bang YJ, Borbath I, Lombard-Bohas C, Valle J, Metrakos P, Smith D, Vinik A, Chen JS, Horsch D, Hammel P, Wiedenmann B, Van Cutsem E, Patyna S, Lu DR, Blanckmeister C, Chao R, Ruszniewski P: Sunitinib malate for the treatment of pancreatic neuroendocrine tumors. N Engl J Med 2011;364:501-513.

18 Mork H, Ignee A, Schuessler G, Ott M, Dietrich CF: Analysis of neuroendocrine tumour metastases in the liver using contrast enhanced ultrasonography. Scand J Gastroenterol 2007;42:652-662.

19 Hoeffel C, Job L, Ladam-Marcus V, Vitry F, Cadiot G, Marcus C: Detection of hepatic metastases from carcinoid tumor: prospective evaluation of contrast-enhanced ultrasonography. Dig Dis Sci 2009;54:2040-2046.
Assessment of Neuroendocrine Liver

Metastases
Neuroendocrinology 2018;106:74-88 DOI: $10.1159 / 000479293$ 
20 Soyer P, Gueye C, Somveille E, Laissy JP, Scherrer A: MR diagnosis of hepatic metastases from neuroendocrine tumors versus hemangiomas: relative merits of dynamic gadolinium chelate-enhanced gradient-recalled echo and unenhanced spin-echo images. AJR Am J Roentgenol 1995; 165:1407-1413.

21 Berger JF, Laissy JP, Limot O, Henry-Feugeas MC, Cadiot G, Mignon M, Schouman-Claeys E: Differentiation between multiple liver hemangiomas and liver metastases of gastrinomas: value of enhanced MRI. J Comput Assist Tomogr 1996;20:349-355.

22 Malago R, D’Onofrio M, Zamboni GA, Faccioli N, Falconi M, Boninsegna L, Mucelli RP: Contrast-enhanced sonography of nonfunctioning pancreatic neuroendocrine tumors. AJR Am J Roentgenol 2009;192:424-430.

23 Wank SA, Doppman JL, Miller DL, Collen MJ, Maton PN, Vinayek R, Slaff JI, Norton JA, Gardner JD, Jensen RT: Prospective study of the ability of computed axial tomography to localize gastrinomas in patients with Zollinger-Ellison syndrome. Gastroenterology 1987;92:905-912.

24 Oliver JH 3rd, Baron RL, Federle MP, Jones BC, Sheng R: Hypervascular liver metastases: do unenhanced and hepatic arterial phase CT images affect tumor detection? Radiology 1997;205:709-715.

25 Oliver JH 3rd, Baron RL, Federle MP, Rockette HE Jr: Detecting hepatocellular carcinoma: value of unenhanced or arterial phase CT imaging or both used in conjunction with conventional portal venous phase contrastenhanced CT imaging. AJR Am J Roentgenol 1996; 167:71-77.

26 Foley WD, Mallisee TA, Hohenwalter MD, Wilson CR, Quiroz FA, Taylor AJ: Multiphase hepatic CT with a multirow detector CT scanner. AJR Am J Roentgenol 2000;175: 679-685.

27 Stafford-Johnson DB, Francis IR, Eckhauser FE, Knol JA, Chang AE: Dual-phase helical CT of nonfunctioning islet cell tumors. J Comput Assist Tomogr 1998;22:335-339.

28 Stafford Johnson DB, Francis IR, Eckhauser FE, Knol JA, Chang AE: Dual-phase helical CT of nonfunctioning islet cell tumors. J Comput Assist Tomogr 1998;22:59-63.

29 Paulson EK, McDermott VG, Keogan MT, DeLong DM, Frederick MG, Nelson RC: Carcinoid metastases to the liver: role of triplephase helical CT. Radiology 1998;206:143150.

30 Ronot M, Cuccioli F, Dioguardi Burgio M, Vullierme MP, Hentic O, Ruszniewski P, d'Assignies G, Vilgrain V: Neuroendocrine liver metastases: vascular patterns on triplephase MDCT are indicative of primary tumour location. Eur J Radiol 2017;89:156-162.

31 Bader TR, Semelka RC, Chiu VC, Armao DM, Woosley JT: MRI of carcinoid tumors: spectrum of appearances in the gastrointestinal tract and liver. J Magn Reson Imaging 2001; 14:261-269.
32 Dromain C, de Baere T, Baudin E, Galline J, Ducreux M, Boige V, Duvillard P, Laplanche A, Caillet H, Lasser P, Schlumberger M, Sigal $\mathrm{R}$ : MR imaging of hepatic metastases caused by neuroendocrine tumors: comparing four techniques. AJR Am J Roentgenol 2003;180: 121-128.

33 Semelka RC, Custodio CM, Cem Balci N, Woosley JT: Neuroendocrine tumors of the pancreas: spectrum of appearances on MRI. J Magn Reson Imaging 2000;11:141-148.

34 Carlson B, Johnson CD, Stephens DH, Ward EM, Kvols LK: MRI of pancreatic islet cell carcinoma. J Comput Assist Tomogr 1993;17: 735-740.

35 Zech CJ, Herrmann KA, Dietrich O, Horger W, Reiser MF, Schoenberg SO: Black-blood diffusion-weighted EPI acquisition of the liver with parallel imaging: comparison with a standard T2-weighted sequence for detection of focal liver lesions. Invest Radiol 2008;43: 261-266.

36 Nasu K, Kuroki Y, Nawano S, Kuroki S, Tsukamoto T, Yamamoto S, Motoori K, Ueda T: Hepatic metastases: diffusion-weighted sensitivity-encoding versus SPIO-enhanced MR imaging. Radiology 2006;239:122-130.

37 d'Assignies G, Fina P, Bruno O, Vullierme MP, Tubach F, Paradis V, Sauvanet A, Ruszniewski P, Vilgrain V: High sensitivity of diffusion-weighted MR imaging for the detection of liver metastases from neuroendocrine tumors: Comparison with T2-weighted and dynamic gadolinium-enhanced MR imaging. Radiology 2013;268:390-399.

38 Moryoussef F, de Mestier L, Belkebir M, Deguelte-Lardiere $\mathrm{S}$, Brixi $\mathrm{H}$, Kianmanesh $\mathrm{R}$, Hoeffel C, Cadiot G: Impact of liver and whole-body diffusion-weighted MRI for neuroendocrine tumors on patient management: a pilot study. Neuroendocrinology 2017;104: 264-272.

39 De Robertis R, D’Onofrio M, Zamboni G, Tinazzi Martini P, Gobbo S, Capelli P, Butturini G, Girelli R, Ortolani S, Cingarlini S, Pederzoli P, Scarpa A: Pancreatic neuroendocrine neoplasms: clinical value of diffusion-weighted imaging. Neuroendocrinology 2016;103:758-770.

40 Reimer P, Rummeny EJ, Shamsi K, Balzer T, Daldrup HE, Tombach B, Hesse T, Berns T, Peters PE: Phase II clinical evaluation of GdEOB-DTPA: dose, safety aspects, and pulse sequence. Radiology 1996;199:177-183.

41 Muhi A, Ichikawa T, Motosugi U, Sou H, Nakajima H, Sano K, Sano M, Kato S, Kitamura T, Fatima Z, Fukushima K, Iino H, Mori Y, Fujii H, Araki T: Diagnosis of colorectal hepatic metastases: comparison of contrast-enhanced CT, contrast-enhanced us, superparamagnetic iron oxide-enhanced MRI, and gadoxetic acid-enhanced MRI. J Magn Reson Imaging 2011;34:326-335.
42 Sankowski AJ, Cwikla JB, Nowicki ML, Chaberek S, Pech M, Lewczuk A, Walecki J: The clinical value of MRI using single-shot echoplanar DWI to identify liver involvement in patients with advanced gastroenteropancreatic-neuroendocrine tumors (GEP-NETs), compared to FSE T2 and FFE T1 weighted image after i.v. Gd-EOB-DTPA contrast enhancement. Med Sci Monit 2012;18:MT33MT40.

43 Koh DM, Collins DJ, Wallace T, Chau I, Riddell AM: Combining diffusion-weighted MRI with Gd-EOB-DTPA-enhanced MRI improves the detection of colorectal liver metastases. Br J Radiol 2012;85:980-989.

44 Kim YK, Lee MW, Lee WJ, Kim SH, Rhim H, Lim JH, Choi D, Kim YS, Jang KM, Lee SJ, Lim HK: Diagnostic accuracy and sensitivity of diffusion-weighted and of gadoxetic acidenhanced 3-T MR imaging alone or in combination in the detection of small liver metastasis $(\leq 1.5 \mathrm{~cm}$ in diameter). Invest Radiol 2012;47:159-166.

45 Song KD, Kim YK, Lee WJ, Lee MW, Park MJ, Hwang J, Lee MH: Detection and characterization of small focal hepatic lesions $(\leq 2.5$ $\mathrm{cm}$ in diameter): a comparison of diffusionweighted images before and after administration of gadoxetic acid disodium at 3.0T. Acta Radiol 2012;53:485-493.

46 Vilgrain V, Esvan M, Ronot M, CaumontPrim A, Aube C, Chatellier G: A meta-analysis of diffusion-weighted and gadoxetic acidenhanced MR imaging for the detection of liver metastases. Eur Radiol 2016;26:45954615.

47 Schreiter NF, Nogami M, Steffen I, Pape UF, Hamm B, Brenner W, Rottgen R: Evaluation of the potential of PET-MRI fusion for detection of liver metastases in patients with neuroendocrine tumours. Eur Radiol 2012;22: 458-467.

48 Frucht H, Doppman JL, Norton JA, Miller DL, Dwyer AJ, Frank JA, Vinayek R, Maton PN, Jensen RT: Gastrinomas: comparison of MR imaging with CT, angiography, and US. Radiology 1989;171:713-717.

49 Gibril F, Jensen RT: Comparative analysis of diagnostic techniques for localization of gastrointestinal neuroendocrine tumors. Yale J Biol Med 1997;70:509-522.

50 Chiti A, Fanti S, Savelli G, Romeo A, Bellanova B, Rodari M, van Graafeiland BJ, Monetti N, Bombardieri E: Comparison of somatostatin receptor imaging, computed tomography and ultrasound in the clinical management of neuroendocrine gastro-entero-pancreatic tumours. Eur J Nucl Med 1998;25:1396-1403.

51 Cwikla JB, Buscombe JR, Caplin ME, Watkinson AF, Walecki J, Gorczyca-Wisniewska E, Hilson AJ: Diagnostic imaging of carcinoid metastases to the abdomen and pelvis. Med Sci Monit 2004;10(suppl 3):9-16. 
52 Dromain C, de Baere T, Lumbroso J, Caillet H, Laplanche A, Boige V, Ducreux M, Duvillard P, Elias D, Schlumberger M, Sigal R, Baudin E: Detection of liver metastases from endocrine tumors: a prospective comparison of somatostatin receptor scintigraphy, computed tomography, and magnetic resonance imaging. J Clin Oncol 2005;23:70-78.

53 Seemann MD: Detection of metastases from gastrointestinal neuroendocrine tumors: prospective comparison of 18F-TOCA PET, triple-phase CT, and PET/CT. Technol Cancer Res Treat 2007;6:213-220.

54 Rockall AG, Planche K, Power N, Nowosinska E, Monson JP, Grossman AB, Reznek RH: Detection of neuroendocrine liver metastases with MnDPDP-enhanced MRI. Neuroendocrinology 2009;89:288-295.

55 Chambers AJ, Pasieka JL, Dixon E, Rorstad O: Role of imaging in the preoperative staging of small bowel neuroendocrine tumors. J Am Coll Surg 2010;211:620-627.

56 Elias D, Lefevre JH, Duvillard P, Goere D, Dromain C, Dumont F, Baudin E: Hepatic metastases from neuroendocrine tumors with a "thin slice" pathological examination: they are many more than you think. Ann Surg 2010;251:307-310.

57 Giesel FL, Kratochwil C, Mehndiratta A, Wulfert S, Moltz JH, Zechmann CM, Kauczor HU, Haberkorn U, Ley S: Comparison of neuroendocrine tumor detection and characterization using DOTATOC-PET in correlation with contrast enhanced CT and delayed contrast enhanced MRI. Eur J Radiol 2012;81: 2820-2825.

58 Schraml C, Schwenzer NF, Sperling O, Aschoff P, Lichy MP, Muller M, Brendle C, Werner MK, Claussen CD, Pfannenberg C: Staging of neuroendocrine tumours: comparison of $\left[{ }^{68} \mathrm{Ga}\right]$ DOTATOC multiphase PET/CT and whole-body MRI. Cancer Imaging 2013; 13:63-72.

59 Shi W, Johnston CF, Buchanan KD, Ferguson WR, Laird JD, Crothers JG, McIlrath EM: Localization of neuroendocrine tumours with [111In] DTPA-octreotide scintigraphy (octreoscan): a comparative study with CT and MR imaging. QJM 1998;91:295-301.

60 Mikolajczak R, Maecke HR: Radiopharmaceuticals for somatostatin receptor imaging. Nucl Med Rev Cent East Eur 2016;19:126-132.

61 Hubalewska-Dydejczyk A, Fross-Baron K, Mikolajczak R, Maecke HR, Huszno B, Pach D, Sowa-Staszczak A, Janota B, Szybinski P, Kulig J: ${ }^{99 m}$ Tc-EDDA/HYNIC-octreotate scintigraphy, an efficient method for the detection and staging of carcinoid tumours: results of 3 years' experience. Eur J Nucl Med Mol Imaging 2006;33:1123-1133.

62 Ezziddin S, Logvinski T, Yong-Hing C, Ahmadzadehfar $\mathrm{H}$, Fischer HP, Palmedo $\mathrm{H}$, Bucerius J, Reinhardt MJ, Biersack HJ: Factors predicting tracer uptake in somatostatin receptor and MIBG scintigraphy of metastatic gastroenteropancreatic neuroendocrine tumors. J Nucl Med 2006;47:223-233.
63 Adams S, Baum R, Rink T, Schumm-Drager PM, Usadel KH, Hor G: Limited value of fluorine-18 fluorodeoxyglucose positron emission tomography for the imaging of neuroendocrine tumours. Eur J Nucl Med 1998;25: 79-83.

64 Binderup T, Knigge U, Loft A, Federspiel B, Kjaer A: 18F-fluorodeoxyglucose positron emission tomography predicts survival of patients with neuroendocrine tumors. Clin Cancer Res 2010;16:978-985.

65 Garin E, Le Jeune F, Devillers A, Cuggia M, de Lajarte-Thirouard AS, Bouriel C, Boucher E, Raoul JL: Predictive value of 18 F-FDG PET and somatostatin receptor scintigraphy in patients with metastatic endocrine tumors. J Nucl Med 2009;50:858-864.

66 Abgral R, Leboulleux S, Deandreis D, Auperin A, Lumbroso J, Dromain C, Duvillard P, Elias D, de Baere T, Guigay J, Ducreux M, Schlumberger M, Baudin E: Performance of (18)fluorodeoxyglucose-positron emission tomography and somatostatin receptor scintigraphy for high Ki67 (>/=10\%) well-differentiated endocrine carcinoma staging. J Clin Endocrinol Metab 2011;96:665-671.

67 Chan DL, Pavlakis N, Schembri GP, Bernard EJ, Hsiao E, Hayes A, Barnes T, Diakos C, Khasraw M, Samra J, Eslick E, Roach PJ, Engel A, Clarke SJ, Bailey DL: Dual somatostatin receptor/FDG PET/CT imaging in metastatic neuroendocrine tumours: proposal for a novel grading scheme with prognostic significance. Theranostics 2017;7:1149-1158.

68 Kayani I, Bomanji JB, Groves A, Conway G, Gacinovic S, Win T, Dickson J, Caplin M, Ell PJ: Functional imaging of neuroendocrine tumors with combined PET/CT using 68Ga-DOTATATE (DOTA-DPhe1,Tyr3-octreotate) and 18F-FDG. Cancer 2008;112:2447-2455.

69 Ambrosini V, Tomassetti P, Castellucci P, Campana D, Montini G, Rubello D, Nanni C, Rizzello A, Franchi R, Fanti S: Comparison between 68Ga-DOTA-NOC and 18F-DOPA PET for the detection of gastro-entero-pancreatic and lung neuro-endocrine tumours. Eur J Nucl Med Mol Imaging 2008;35:14311438.

70 Hoegerle S, Altehoefer C, Ghanem N, Koehler G, Waller CF, Scheruebl H, Moser E, Nitzsche E: Whole-body 18F DOPA PET for detection of gastrointestinal carcinoid tumors. Radiology 2001;220:373-380.

71 Nikolaou A, Thomas D, Kampanellou C, Alexandraki K, Andersson LG, Sundin A, Kaltsas G: The value of 11C-5-hydroxy-tryptophan positron emission tomography in neuroendocrine tumor diagnosis and management: experience from one center. J Endocrinol Invest 2010;33:794-799.

72 Frilling A, Sotiropoulos GC, Radtke A, Malago M, Bockisch A, Kuehl H, Li J, Broelsch CE: The impact of 68Ga-DOTATOC positron emission tomography/computed tomography on the multimodal management of patients with neuroendocrine tumors. Ann Surg 2010;252:850-856.
73 Ruf J, Heuck F, Schiefer J, Denecke T, Elgeti F, Pascher A, Pavel M, Stelter L, Kropf S, Wiedenmann B, Amthauer H: Impact of multiphase 68Ga-DOTATOC-PET/CT on therapy management in patients with neuroendocrine tumors. Neuroendocrinology 2010;91:101109.

74 Wild D, Fani M, Behe M, Brink I, Rivier JE, Reubi JC, Maecke HR, Weber WA: First clinical evidence that imaging with somatostatin receptor antagonists is feasible. J Nucl Med 2011;52:1412-1417.

75 Deppen SA, Blume J, Bobbey AJ, Shah C, Graham MM, Lee P, Delbeke D, Walker RC: 68Ga-DOTATATE compared with 111InDTPA-octreotide and conventional imaging for pulmonary and gastroenteropancreatic neuroendocrine tumors: a systematic review and meta-analysis. J Nucl Med 2016;57:872878.

76 Armbruster M, Sourbron S, Haug A, Zech CJ, Ingrisch $\mathrm{M}$, Auernhammer CJ, Nikolaou K, Paprottka PM, Rist C, Reiser MF, Sommer WH: Evaluation of neuroendocrine liver metastases: a comparison of dynamic contrastenhanced magnetic resonance imaging and positron emission tomography/computed tomography. Invest Radiol 2014;49:7-14.

77 Pfeifer A, Knigge U, Binderup T, Mortensen J, Oturai P, Loft A, Berthelsen AK, Langer SW, Rasmussen P, Elema D, von Benzon E, Hojgaard L, Kjaer A: 64Cu-DOTATATE PET for neuroendocrine tumors: a prospective head-to-head comparison with 111In-DTPAoctreotide in 112 patients. J Nucl Med 2015; $56: 847-854$

78 Johnbeck CB, Knigge U, Loft A, Berthelsen AK, Mortensen J, Oturai P, Langer SW, Elema DR, Kjaer A: Head-to-head comparison of 64Cu-DOTATATE and 68Ga-DOTATOC PET/CT: a prospective study of 59 patients with neuroendocrine tumors. J Nucl Med 2017;58:451-457.

79 Hallet J, Gayet B, Tsung A, Wakabayashi G, Pessaux P; 2nd International Consensus Conference on Laparoscopic Liver Resection Group: Systematic review of the use of preoperative simulation and navigation for hepatectomy: current status and future perspectives. J Hepatobiliary Pancreat Sci 2015;22: 353-362.

80 Radtke A, Sotiropoulos GC, Molmenti EP, Schroeder T, Peitgen HO, Frilling A, Broering DC, Broelsch CE, Malago M: Computer-assisted surgery planning for complex liver resections: when is it helpful? A single-center experience over an 8-year period. Ann Surg 2010;252:876-883.

81 Barbaro B, Soglia G, Alvaro G, Vellone M, Giuliante F, Nuzzo G, Bonomo L: Hepatic veins in presurgical planning of hepatic resection: what a radiologist should know. Abdom Imaging 2013;38:442-460.
Assessment of Neuroendocrine Liver

Metastases
Neuroendocrinology 2018;106:74-88 DOI: $10.1159 / 000479293$ 
82 Albanus DR, Apitzsch J, Erdem Z, Erdem O, Verburg FA, Behrendt FF, Mottaghy FM, Heinzel A: Clinical value of ${ }^{68} \mathrm{Ga}$-DOTATATE-PET/CT compared to stand-alone contrast enhanced CT for the detection of extra-hepatic metastases in patients with neuroendocrine tumours (NET). Eur J Radiol 2015; 84:1866-1872.

83 Etchebehere EC, de Oliveira Santos A, Gumz B, Vicente A, Hoff PG, Corradi G, Ichiki WA, de Almeida Filho JG, Cantoni S, Camargo EE, Costa FP: 68Ga-DOTATATE PET/CT, ${ }^{99 \mathrm{~m} T \mathrm{Tc}-H Y N I C-o c t r e o t i d e}$ SPECT/CT, and whole-body MR imaging in detection of neuroendocrine tumors: a prospective trial. J Nucl Med 2014;55:1598-1604.

84 Fendler WP, Barrio M, Spick C, Allen-Auerbach M, Ambrosini V, Benz M, Bluemel C, Grewal RK, Lapa C, Miederer M, Nicolas G, Schuster T, Czernin J, Herrmann K: 68GaDOTATATE PET/CT interobserver agreement for neuroendocrine tumor assessment: results of a prospective study on 50 patients. J Nucl Med 2017;58:307-311.

85 Frilling A, Sotiropoulos GC, Li J, Kornasiewicz O, Plockinger U: Multimodal management of neuroendocrine liver metastases. HPB (Oxford) 2010;12:361-379.

86 Lebtahi R, Cadiot G, Delahaye N, Genin R, Daou D, Peker MC, Chosidow D, Faraggi M, Mignon M, Le Guludec D: Detection of bone metastases in patients with endocrine gastroenteropancreatic tumors: bone scintigraphy compared with somatostatin receptor scintigraphy. J Nucl Med 1999;40:1602-1608.

87 Frilling A, Malago M, Martin H, Broelsch CE: Use of somatostatin receptor scintigraphy to image extrahepatic metastases of neuroendocrine tumors. Surgery 1998;124:1000-1004.

88 Norlen O, Stalberg P, Oberg K, Eriksson J, Hedberg J, Hessman O, Janson ET, Hellman P, Akerstrom G: Long-term results of surgery for small intestinal neuroendocrine tumors at a tertiary referral center. World J Surg 2012; 36:1419-1431.
89 Clift AK, Faiz O, Al-Nahhas A, Bockisch A, Liedke MO, Schloericke E, Wasan H, Martin J, Ziprin P, Moorthy K, Frilling A: Role of staging in patients with small intestinal neuroendocrine tumours. J Gastrointest Surg 2016;20:180-188; discussion 188.

90 Givi B, Pommier SJ, Thompson AK, Diggs BS, Pommier RF: Operative resection of primary carcinoid neoplasms in patients with liver metastases yields significantly better survival. Surgery 2006; 140:891-897; discussion 897898.

91 Chambers AJ, Pasieka JL, Dixon E, Rorstad O: The palliative benefit of aggressive surgical intervention for both hepatic and mesenteric metastases from neuroendocrine tumors. Surgery 2008;144:645-651; discussion 651643.

92 Capurso G, Bettini R, Rinzivillo M, Boninsegna L, Delle Fave G, Falconi M: Role of resection of the primary pancreatic neuroendocrine tumour only in patients with unresectable metastatic liver disease: a systematic review. Neuroendocrinology 2011;93:223229.

93 Capurso G, Rinzivillo M, Bettini R, Boninsegna L, Delle Fave G, Falconi M: Systematic review of resection of primary midgut carcinoid tumour in patients with unresectable liver metastases. Br J Surg 2012;99:1480-1486.

94 Wallace S, Ajani JA, Charnsangavej C, DuBrow R, Yang DJ, Chuang VP, Carrasco CH, Dodd GD Jr: Carcinoid tumors: imaging procedures and interventional radiology. World J Surg 1996;20:147-156.

95 Woodard PK, Feldman JM, Paine SS, Baker ME: Midgut carcinoid tumors: CT findings and biochemical profiles. J Comput Assist Tomogr 1995; 19:400-405.

96 Pantongrag-Brown L, Buetow PC, Carr NJ, Lichtenstein JE, Buck JL: Calcification and fibrosis in mesenteric carcinoid tumor: CT findings and pathologic correlation. AJR Am J Roentgenol 1995;164:387-391.

97 Horton KM, Kamel I, Hofmann L, Fishman EK: Carcinoid tumors of the small bowel: a multitechnique imaging approach. AJR Am J Roentgenol 2004;182:559-567.
98 Frilling A, Giele H, Vrakas G, Reddy S, Macedo R, Al-Nahhas A, Wasan H, Clift AK, Gondolesi GE, Vianna RM, Friend P, Vaidya A: Modified liver-free multivisceral transplantation for a metastatic small bowel neuroendocrine tumor: a case report. Transplant Proc 2015;47:858-862.

99 Lardiere-Deguelte S, de Mestier L, Appere F, Vullierme MP, Zappa M, Hoeffel C, Noaves M, Brixi H, Hentic O, Ruszniewski P, Cadiot G, Panis Y, Kianmanesh R: Toward preoperative classification of lymph-node metastases in patients with small intestine neuroendocrine tumours in the era of intestinalsparing surgery. Neuroendocrinology 2016; 103:552-559.

100 Beiderwellen KJ, Poeppel TD, HartungKnemeyer V, Buchbender C, Kuehl H, Bockisch A, Lauenstein TC: Simultaneous 68Ga-DOTATOC PET/MRI in patients with gastroenteropancreatic neuroendocrine tumors: initial results. Invest Radiol 2013;48:273-279.

101 Kumbasar B, Kamel IR, Tekes A, Eng J, Fishman EK, Wahl RL: Imaging of neuroendocrine tumors: accuracy of helical CT versus SRS. Abdom Imaging 2004;29:696-702.

102 Elias D, Sideris L, Liberale G, Ducreux M, Malka D, Lasser P, Duvillard P, Baudin E: Surgical treatment of peritoneal carcinomatosis from well-differentiated digestive endocrine carcinomas. Surgery 2005; 137:411416.

103 Vasseur B, Cadiot G, Zins M, Flejou JF, Belghiti J, Marmuse JP, Vilgrain V, Bernades $P$, Mignon M, Ruszniewski P: Peritoneal carcinomatosis in patients with digestive endocrine tumors. Cancer 1996;78:1686-1692.

104 de Mestier L, Lardiere-Deguelte S, Brixi H, O’Toole D, Ruszniewski P, Cadiot G, Kianmanesh R: Updating the surgical management of peritoneal carcinomatosis in patients with neuroendocrine tumors. Neuroendocrinology 2015;101:105-111. 